\title{
SONGKET MELAYU: SERUMPUN BANGSA SESANTUN BUDAYA
}

\author{
(MALAY SONGKET: THE SYMBOL OF BLOOD BROTHERHOOD AND ETIQUETTE \\ CULTURE)
}

Arba'iyah Ab. Aziz

arbaiyah@uitm.edu.my

Fakulti Seni Lukis dan Seni Reka

Universiti Teknologi MARA, Shah Alam

Malaysia

Received: 25th August 2021; Accepted: 7th October 2021; Published: 26th October 2021

\begin{abstract}
History has shown that the "songket" is in a class of its own in the socio-culture of Malays in the Malay Archipelago. Fundamentally, "songket" and its wearing have been the symbol of acceptance and the collective instillation of cultural values. The textile was created based on cross- and multi-cultural elements that have long been established and further assimilated into society today. Therefore, this study aims to trace the beginnings and roles of the royal institutions in spreading this heritage art between Malaysia and Indonesia, specifically for "songket" Terengganu and Riau. The research focuses on the similarities based on acculturation and assimilation of culture. This study is critical as a form of knowledge documentation for both countries, which share similar connections and homogenous values. The research employs the qualitative approach, with a focus on observation and conducting interviews. A secondary study is also conducted to analyse the historical and socio-cultural aspects involved. Interview subjects from both countries were chosen based on specific fields and locations. Each finding leads and adds to the existing body of knowledge. Since issues on the Malay World usually take on a broader outlook, the implications of the study can contribute to the ethnic group itself, especially the scholars, weavers, cultural activists, art historians and the community at large. Based on the quality and uniqueness of the "songket", there is no doubt that the textile should be acknowledged as one of the greatest heritage art, saturated with civil values and symbols of the finesse of the Malays.
\end{abstract}

Keywords: songket, assimilation, weavers, Terengganu, Riau.

\begin{abstract}
Abstrak
Sejarah membuktikan bahawa songket mempunyai kedudukan dan peranannya yang teristimewa dalam sosio-budaya masyarakat di rantau Melayu. Kajian ini menelusuri sejarah titik mula dan peranan institusi Diraja dalam menyebarluaskan seni warisan rumpun Melayu antara Malaysia dan Indonesia khususnya melibatkan songket Terengganu dan songket Riau. Songket dan pemakaiannya adalah menjadi lambang kepada penerimaan dan penyerapan nilai budaya secara kolektif. Ia terbina di atas landasan rentas dan silang budaya yang sudah bertapak lama dan semakin sebati sehingga ke hari ini. Satu kajian mengenai aspek persamaan
\end{abstract}


dilakukan bersandarkan asimilasi dan akulturasi budaya. Justeru, kajian ini dianggap penting sebagai pendokumentasian ilmu untuk kedua-dua buah negara yang mempunyai rantaian dan pertalian yang hampir sama ke atas nilai budaya yang bersifat 'homogeneous'. Penyelidikan ini adalah berteraskan kepada kaedah kualitatif dengan tertumpu kepada kaedah observasi dan temu bual. Selain itu, kajian sekunder turut meneliti aspek kajian historikal dan sosiobudaya. Beberapa informan dari kedua-dua negara dipilih mengikut spesifikasi bidang dan tempat. Jelasnya, setiap perolehan jumpaan menemukan sumber keilmuan yang sangat bermakna. Memandangkan persoalan tentang dunia dan alam budaya Melayu ini bersifat serantau dan sejagat, maka sewajarnya penyelidikan seumpamanya dapat memberi manfaat kepada bangsa Melayu seluruhnya khususnya kepada golongan sarjana, pendidik, penenun, budayawan, seniman, aktivis budaya, sejarawan seni, peniaga, pencipta seni dan masyarakat seluruhnya. Bersandarkan kepada kualiti dan keunikannya, songket sememangnya wajar diiktiraf sebagai seni warisan agung yang unggul serta kaya dengan nilai peradaban dan lambang kesantunan budi bagi kehidupan dan kemanusiaan bangsa Melayu.

Kata Kunci: songket, asimilasi, penenun, Terengganu, Riau.

\section{Pengenalan}

Masyarakat dunia sentiasa bertindak untuk menghasilkan pelbagai jenis tekstil daripada bahan-bahan alam semula jadi seperti kulit kayu, serat-serat dedaunan, sumber binatang dan sebagainya dalam penghasilan pelbagai jenis fabrik. Ia adalah bertujuan bagi memenuhi keperluan asasi dalam kehidupan manusia dan menjadi pemakaian budaya. Justeru, seni reka tekstil terus berkembang seiring dengan perkembangan budaya sesuatu kelompok manusia sekali gus membentuk asas ketamadunannya.

Adalah dipercayai, seni tenunan telahpun wujud sejak 500 tahun sebelum Masihi lagi, iaitu di Mesopotamia dan Mesir. Kemudian seni ini berkembang ke Eropah dan Asia, termasuklah di Indonesia dan Semenanjung Tanah Melayu terutama di Kelantan, Pahang, Terengganu, serta meliputi Sabah dan Sarawak yang turut menjadi pusat aktiviti menenun di Malaysia (Habibah Abdul Jabbar, Nor Azlin Hamidon, Muhammad Ismail Abdul Kadir \& Abdul Razak Abdul Jabbar, 2019). Antara seni tenunan yang dianggap sebagai ratu fabrik tekstil ialah seni tenunan songket Melayu.

Hill (1948) menjelaskan, menenun adalah perusahaan tradisi yang diusahakan di Terengganu dan Kelantan dengan penggunaan alat tradisi kek berkaki manakala songket adalah antara yang terbaik berbanding tekstil-tekstil Melayu yang lain. Menurut R.O. Windstedt (1909), songket terhasil selepas dari kain Cindai atau Limar. Penenun songket tempatan mula berkecimpung ketika kemasukan benang emas di Tanah Melayu. Benang emas telah diketahui menjadi bahan eksport negeri China ke negeri-negeri rantau ini selain bahan sutera.

Kemasyhuran seni tenunan songket tidak perlu disangkal lagi kerana kaya dengan nilai keindahan dan sarat dengan maknanya sama ada secara tersurat mahupun yang tersirat. Ertinya songket memang elok dari segi kehalusan seni Melayu di samping ketinggian nilai falsafah yang mengiringi motif-motif pilihan serta tatacara adat pemakaiannya (Arba'iyah Ab. Aziz, 2018). Justeru, amat bertepatan dengan ungkapan yang diberi "songket sebagai seni warisan agung" atau "songket sebagai ratu fabrik" apabila kesohoran seni dan pemakaiannya berkembang luas bukan sahaja di Malaysia, malah meliputi Indonesia, Brunei dan Singapura. 
Songket sering dikaitkan dengan kesenian istana pada zaman silam dalam konteks tradisi agung. Pada mulanya songket ditenun khas untuk kegunaan Diraja dan golongan bangsawan dengan gubahan pemakaian benang sutera dan benang emas. Ia meletakkan suatu bentuk sistem pemakaian, makna hirarki dan status dalam masyarakat. Dalam konteks ini, songket diadun eksklusif untuk golongan tertentu yang membawa makna tersebut (Rahmah Bujang \& Nor Azlin Hamidon, 2002). Wujud juga penaungan tertentu yang menghadkan pemakaiannya dan hanya dilanggani pemerintah-pemerintah tertentu dan tidak kepada orang-orang kebiasaan (Grace I. Selvanayagam, 1990).

Sebagai seni fabrik yang halus serta tinggi mutu keasliannya, songket yang diwarisi disandarkan dengan nilai budaya unggul. Dalam Hikayat-Hikayat Melayu lama seperti Sejarah Melayu, Hikayat Hang Tuah mahupun dalam Hikayat Raja-raja Pasai tidak terdapat perkataan songket, sebaliknya yang disebut ialah "kain berpakan emas" yang merujuk kepada penggunaan benang emas dalam tenunan kain songket seperti benang pakan (Azah Aziz, 2006).

Alam Melayu atau Nusantara turut dikenali sebagai wilayah budaya tekstil yang memberikan identiti lokaliti berdasarkan jenis tekstil yang dihasilkan. Perkembangan tenunan di Tanah Melayu dikatakan ada hubungan dengan pedagang-pedagang dari Jawa, Kepulauan Maluku, Borneo dan Bugis. Dari segi sejarah, Kelantan dan Terengganu adalah sebahagian dari jajahan Kerajaan Sriwijaya yang bertapak di Palembang. Bermula dari abad ke-9 Masihi, kerajaan ini telah melebar luas pengaruhnya ke Langkasuka (Kerajaan BuddhaMelayu terawal di Kedah) dan Pahang. Hal ini bererti, sejarah rumpun Melayu sudahpun bertapak lama sehingga mewujudkan rentas silang budaya yang semakin sebati hingga ke hari ini.

Disebabkan faktor pensejarahan yang terjalin, maka wujud pengaruh penyerapan antara satu tempat dengan kawasan yang lain. Lebih-lebih lagi apabila kegiatan menenun ini terus dinaungi oleh pihak istana dan pemerintah sebagai sumber sosioekonomi dan aktiviti sosiobudaya masyarakat setempat. Tradisi ini terus kekal dan dipertahankan sehingga ke hari ini sebagai seni warisan bangsa. Walau bagaimanapun, wujud persamaan antara songket Malaysia dengan songket dari negara-negara lain. Satu kajian mengenai persamaan wajar dilakukan memandangkan terdapat proses pengasimilasian dan pengakulturasian budaya yang wujud di dunia Melayu. Penulisan ini terhasil setelah melihat dari pelbagai aspek yang wujud antara songket Melayu Terengganu dan songket Riau.

\section{Kajian Literatur}

\section{Hubungan Sosiobudaya Kerajaan Terengganu dan Riau}

Kewujudan kerajaan-kerajaan Melayu awal yang bertaburan di sekitar kepulauan Alam Melayu telah memperluaskan lagi kesenian tekstil dalam kalangan orang Melayu (Kerlogue, 2004). Setiap satunya sudah terjalin hubungan diplomatik dalam konteks pertalian kekeluargaan sama ada melalui hubungan perkahwinan mahupun pertalian rakan dagangan di luar Alam Melayu. Kewujudan empayar-empayar di Alam Melayu dengan sistem pemerintahan monarki turut membantu mengukuhkan lagi lapangan seni budaya dan ekonomi. Golongan Diraja dan bangsawan berperanan sebagai penaung dalam memupuk jalinan budaya di Alam Melayu. Golongan tersebut menjadi katalis kepada pembangunan dan perkembangan seni budaya bangsanya. 
Di samping itu, aspek kearifan, bakat, kreativiti dan ketinggian kemahiran dalam kalangan orang Melayu menyerlahkan lagi perkembangan aktiviti mereka. Perkara ini diperakui sendiri oleh ramai para sarjana Barat termasuk R.O Winstedt, Sir Richard James Wilkinson dan Mubin Sheppard. Hubungan sosiobudaya antara negara tetangga seperti Malaysia dan Indonesia menjadi sandaran kepada pertembungan tersebut. Songket dan pemakaiannya seakan menjadi lambang kepada penerimaan dan penyerapan nilai budaya secara kolektif yang sudah wujud berkurun-kurun lamanya. Oleh yang demikian, kajian ini tertumpu dengan melihat kepada sejarah perkembangan songket Terengganu dan Riau, sebagai suatu pendokumentasian ilmu bagi kedua-dua negara.

Dari segi sejarah, kerajaan-kerajaan Melayu beraja ini menjadi pusat pentadbiran dan pelabuhan bagi segala aktiviti perekonomian dan hubungan diplomatik. Suatu ketika dahulu, kerajaan-kerajaan Melayu ini sememangnya terkenal sebagai pusat pengeluaran dan pengumpulan hasil-hasil bumi tempatan di samping penghasilan produk tekstil tradisi orang Melayu. Banyak hasil bumi seperti kayu-kayan dan rempah-ratus diperdagangkan bersamasama dengan barangan dagangan dari luar seperti benang sutera, emas, perak, seramik dan manik kaca. Tekstil juga telah menjadi salah satu komoditi terpenting dan medium pertukaran dari segi ekonomi antara orang Melayu di sekitar Alam Melayu yang mengamalkan sistem pertukaran barang (Siti Zainon Ismail, 1997).

Dalam abad ke-18 Masihi, jaringan perhubungan kerajaan Riau begitu luas di Alam Melayu khususnya melalui perdagangan dan perkahwinan. Sumber dari Tuhfat al-Nafis menggariskan salasilah tokoh-tokoh Bugis, Melayu dan Siak dalam sejarah, mencatatkan peristiwa perkahwinan antara orang bangsawan Riau dengan Siak, Terengganu, Perak, Kedah, Brunei, Kalimantan Barat dan orang-orang Bugis di Selangor. Umumnya boleh dikatakan bahawa golongan bangsawan Melayu Riau sangat berhubungan dengan Pahang dan Terengganu, manakala orang Bugis Riau pula berhubungan dengan Kalimantan, Perak, Kedah dan Selangor.

Hubungan dan sejarah awal Kerajaan Melayu Terengganu dan Riau bermula daripada hasil perkahwinan antara sultan Terengganu dengan anak raja Riau. Hasil hubungan tersebut telah mewujudkan suatu rantaian budaya yang mempunyai ciri-ciri persamaan dalam konteks sosio-budaya Melayu Nusantara. Kesan daripada proses asimilasi dan akulturasi budaya tersebut, maka terhasillah seni songket Melayu yang diadun rapi serta masyhur sekali penggunaannya bagi kedua-dua negara.

\section{Hubungan antara Kerajaan Terengganu dan Kerajaan Riau.}

Sejarah membuktikan bahawa telah wujud hubungan atau pertalian kekeluargaan menerusi ikatan perkahwinan di antara Terengganu dengan wilayah-wilayah rantau Melayu termasuk Riau. Di atas ikatan kekerabatan itu maka wujudlah pelbagai pengaruh seperti dari segi bahasa, adat, penampilan, pemakaian, kesenian, dan gaya hidup antara mereka (Arba'iyah Mohd Noor \& Norazilawati Abd Wahab, 2019).

Apabila mangkatnya pemerintah Terengganu, iaitu Sultan Zainal Abidin (1) pada 1733-1793, baginda telah digantikan oleh anakanda bungsunya, iaitu Raja Mansur. Sultan Mansur Syah 1 yang pernah menetap di Riau selama 14 tahun dan berkahwin dengan Raja Bulang anakanda kepada Sultan Sulaiman, iaitu Sultan Kerajaan Johor - Riau pada 14 April 1739 (Rogayah A. Hamid \& Mariam Salim, 2006). Baginda mempunyai beberapa orang permaisuri dan antara anakanda puteri baginda bernama Tengku Tipah. Tengku Tipah telah 
dikahwinkan dengan Yam Tuan Raja Siak, Raja Ismail, putera Sultan Mahmud Siak (Rogayah A. Hamid \& Mariam Salim, 2006). Dalam pemerintahan Sultan Sulaiman (mangkat 1760), Sultan Terengganu seringkali mengunjungi istana Riau dan seterusnya baginda membawa unsur-unsur kebudayaan Riau kembali ke kerajaannya di Terengganu. Di sinilah berlakunya apa yang dapat disimpulkan sebagai jalinan persefahaman.

\section{Perusahaan Songket di Terengganu dan Riau}

Disebabkan lokasi dan kedudukan geografi yang strategik di laluan perdagangan maritim Timur-Barat, maka terhasilnya pertembungan dan tautan pelbagai budaya di alam Melayu. Demikian sejarah telah meletakkan Kelantan dan Terengganu menjalani peranannya sebagai pusat perdagangan antara China, India dan Eropah sejak abad ke-16 Masihi lagi (Buhler, 1980).

Berdasarkan catatan China, nama Terengganu antara lain dikenali dengan nama Ting-yu-nung, Ting-chia-lu, atau Teng-ka-lo. Pada tahun 1178 Masihi, Terengganu mencatatkan bahawa kawasan Kuala Berang dikenali dengan nama Fo-lo-an yang beroperasi sebagai sebuah pelabuhan sekali gus menjadi fokus para pedagang khususnya dari Champa, Tambralinga dan lain-lain (Abdul Rahman Abdullah, 2000). Kerajaan ini juga pernah berada bawah kerajaan Melayu di Jambi (Mohd Jamil Mukmin, 1994).

Terengganu terdiri daripada beberapa daerah, iaitu Besut, Dungun, Kemaman, Kuala Berang atau Ulu Terengganu, Kuala Terengganu dan Marang, Paka, Kemasik dan Kertih. Di bahagian timurnya, ia bersempadanan dengan Laut Cina Selatan manakala di bahagian selatan ialah negeri Pahang, Kuala Terengganu ialah ibu negeri Terengganu (Muhammad Yusoff Hashim, 1991).

Perusahaan tradisi songket ini banyak terdapat di Pantai Timur Malaysia, iaitu khususnya di negeri Terengganu sekitar Kuala Terengganu terutamanya di Mukim Losong, termasuk Kampung Losong Panglima Perang dan Kampung Losong Datuk Amar. Kedua-dua kampung ini adalah merupakan kawasan penenun Diraja. Di samping itu, terdapat juga perusahaan menenun songket ini di Mukim Canang Tiga, iaitu di Kampung Nilir, Kampung Tok Nasek dan Kampung Pasir Panjang. Perusahaan menenun songket yang terdapat di persisiran pantai pula ialah di Kampung Bonggol, Kuala Ibai dan Cendering, manakala perusahaan menenun songket ini juga terdapat di kampung yang berhampiran jalan menuju ke Kota Bharu, iaitu Kampung Pulau Rusa dan Kampung Paloh.

Suatu lagi faktor perkembangan tekstil di Terengganu adalah akibat penghijrahan orang-orang Cham ke Terengganu selepas kejatuhan Kerajaan Champa kepada Annam pada tahun 1471. Masyarakat Champa sangat mahir dalam kerja-kerja tangan. Mereka dikatakan telah berhijrah ke Terengganu dan mempraktikkan kemahiran menenun kain. Alat tenun yang digunakan oleh masyarakat Champa dikatakan mempunyai persamaan dengan alat tenun yang digunakan pada hari ini.

Perhubungan dagangan antara Terengganu dengan beberapa wilayah Indonesia telah membuka ruang dan peluang yang cukup besar untuk membolehkan seni tekstil berkembang sebagai sumber ekonomi yang penting (Arba'iyah Mohd Noor \& Norazilawati Abd Wahab, 2019). 


\section{Perusahaan Songket di Riau}

Riau merupakan salah satu wilayah di Indonesia yang terletak di bahagian tengah pulau Sumatera. Wilayah Riau adalah lebih dikenali sebagai daerah daratan dan daerah kepulauan. Riau merupakan wilayah yang kaya dengan sumber alam seperti kayu hutan selain hasil minyak. Penduduk asli Riau ialah bangsa Melayu.

Seni kerajinan yang berupa seni tenunan kain seperti kain songket, pelikat, telepuk dan mastuli dengan hiasan benang emas banyak dijalankan di Pulau Daik Lingga dan Tambelan. Kesenian lainnya adalah seperti anyaman buluh, rotan dan pandan bagi menghasilkan tikar, bakul dan barang-barang keperluan serta perhiasan rumah (Arsitektur Traditional Daerah Riau, 1986/1987).

Di Riau, songket dikategorikan sebagai tenunan manakala aktiviti menenun dikenali sebagai kerajinan. Kerajinan ini pula dikategorikan kepada dua, iaitu kerajinan tangan untuk menghasilkan alat keperluan harian dan kerajinan tangan yang menghasilkan hasilan seni untuk tujuan pasaran.

Adalah sesuatu yang menarik apabila kaedah membuat tenunan songket kini masih dilakukan secara tradisional, iaitu melalui proses menenun benang dengan peralatan dan penggunaan benang emas dan perak. Tenunan songket ini adalah berasal dari Siak. Ia bermula dari kesultanan Siak yang telah memindahkan pusat pemerintahannya dari Siak ke Pekanbaru dan turut melibatkan perpindahan pusat kebudayaan Melayu. Tenun songket Melayu ini menjadi kain tradisional khas Riau (Sasya Lestari, Menul Teguh Riyanti, 2017).

Di daratan pulau Sumatera, aktiviti menenun berkembang sejajar dengan kebesaran kerajaan-kerajaan Melayu daratan seperti Kerajaan Pelalawan (1530-1879), Kerajaan Indragiri (1658-1838) dan Kerajaan Siak Sri Indrapura (1723-1858). Di Daik Lingga, terdapat pelbagai jenis kain yang tinggi mutunya dalam koleksi Said Abdul Hamid. Kain tertua dalam koleksi peribadi masyarakat ialah kain bercual kepala dua benang emas, yang dihasilkan pada abad ke 17. Bermakna kain tersebut telah dihasilkan ketika kerajaan Melayu masih disebut Johor-Riau yakni sebelum dikenali Riau-Lingga. Selain bukti-bukti yang terdapat dalam buku-buku sejarah dan karya sastera khasnya syair, artifak berupa kain lama dalam kategori budaya benda masih tersimpan hingga ke hari ini.

\section{Metodologi Kajian}

Penyelidikan ini menggunakan kaedah kualitatif. Selain memaparkan kajian sekunder berteraskan kajian historikal, penggunaan kajian primer adalah tertumpu kepada kaedah observasi dan temu bual yang digunakan dalam penyelidikan ini. Beberapa informan dari kedua-dua negara telah dipilih mengikut spesifikasi bidang dan kepakaran masing-masing (Rujuk Jadual 1).

Jadual 1: Senarai nama-nama informan yang ditemu bual secara peribadi.

\begin{tabular}{|l|l|l|}
\hline No. & \multicolumn{1}{|c|}{ Nama } & \multicolumn{1}{c|}{ Pekerjaan } \\
\hline 1. & Hajah Mursidah Osman & $\begin{array}{l}\text { Penenun dan pengusaha songket di daerah } \\
\text { Pekanbaru, Riau. }\end{array}$ \\
\hline 2. & Drs. Dt. H.O.k. Nizami Jamil & Ahli Lembaga Warisan Budaya Melayu Riau. \\
\hline
\end{tabular}




\begin{tabular}{|l|l|l|}
\hline 3. & $\begin{array}{l}\text { Ros Diah Harlina Abdul Katar } \\
\text { Ali }\end{array}$ & Penenun dan pengusaha songket di daerah Siak. \\
\hline 4. & Siti Mariam Mamat & Penenun songket di negeri Terengganu. \\
\hline 5. & Wan Manang Wan Awang & $\begin{array}{l}\text { Penenun dan pengusaha songket di negeri } \\
\text { Terengganu. }\end{array}$ \\
\hline
\end{tabular}

\section{Dapatan Kajian}

\section{Persamaan Songket Terengganu dan Songket Riau}

\section{i. Dinaungi Institusi Diraja}

Golongan istana mempunyai bidang autoriti untuk melantik atau memayungi orang-orang yang arif atau ahli dalam sesuatu lapangan tertentu. Seniman atau karyawan yang berkebolehan dilantik menjadi orang istana, dan mereka mempunyai masa dan peluang untuk memperhalusi dan menumpukan sepenuh perhatian dalam bidang masing-masing. Oleh yang demikian, penghasilan seni dapat dikhususkan serta dipertingkatkan mutunya dari masa ke semasa. Mereka bekerja di perkarangan istana bawah naungan sultan, permaisuri dan pembesar-pembesar istana yang amat menitikberatkan aspek ketinggian seni dan reka bentuk bersandarkan kepakaran masing-masing. Ia begitu ketara dalam penciptaan kain dewangga seperti songket, limar dan telepuk (Azah Aziz, 2006).

Bagi mengisi keperluan istana dan juga golongan bangsawan, seniman dari rakyat biasa dijemput untuk ke istana bagi mengolah dan mengubah tenunan songket yang mempamerkan nilai ketinggian seni dan makna (Haziah Hussin, Salmah Abu Mansor, Rahilah Omar, Hapsah Ismail \& Aminuddin Hassan, 2009). Memandangkan golongan pemerintah itu mempunyai kemampuan dari segi kebendaan, maka mereka juga bertindak sebagai penaung untuk membiayai penghasilan seni istana. Penghasilan seni tersebut dapat mencerminkan atau memperkukuhkan kemurnian kedudukan dan status yang dihormati rakyat.

Persamaan ini wujud di kedua-dua buah negara iaitu Terengganu dan Riau, iaitu tempat songket pada suatu ketika dahulu dinaungi golongan istana. Pada masa silam hanya golongan bangsawan sahaja yang mampu memiliki songket daripada sutera dan benang emas. Songket yang disifatkan terbaik dan bermutu tinggi adalah tenunan hasil buatan tangan. Namun, lama-kelamaan kain songket turut dipakai oleh orang kebanyakan terutamanya menjadi pakaian adat kepada pasangan pengantin yang bergelar "raja sehari" (Hajah Mursidah Osman, temu bual peribadi, 16 Disember 2018).

Di kedua-dua wilayah ini merupakan perusahaan songket yang terkenal sejak berabadabad lamanya. Di negeri Terengganu, nama Puan Hajah Ngah Taib, dikenali sebagai seorang pereka ragam hias songket yang telah mewarisi kemahiran menenun dari moyangnya, iaitu Wan Sharifah Haji Abdullah yang berasal dari Kampung Losong Datuk Amar, Terengganu. Beliau mengatakan bahawa tenunan songket telah wujud kira-kira dua ratus tahun yang lalu. Ia mula diperkenalkan pada peringkat istana semasa pemerintahan Sultan Marhum Janggut (1733-1793).

Bersandarkan penceritaannya, Baginda sultan telah menitahkan Datuk Panglima Dalam pergi ke China untuk mendapatkan benang-benang dan bahan pencelup yang 
digunakan untuk meniru kain cindai yang telah lama dikenali dalam kalangan istana. Sekembalinya dari sana, Datuk Panglima Dalam telah meminta ibunya Wan Sharifah untuk membuat tenunan itu. Beberapa alat yang dikenali sebagai kek telah direka sendiri oleh beliau.

Tenunan songket ini seterusnya telah dijadikan pakaian sultan dan golongan istana. Malah Sultan Sulaiman yang memerintah dari tahun 1920 hingga 1942 telah merekacipta motif-motif dan ragam hias untuk dijadikan pakaian songket baginda (Siti Zainon Ismail, 1986). Penenun songket yang terkenal pada waktu itu ialah Wan Minah Pelangi dan sebelum beliau meninggal telah menyerahkan reka corak songket berupa lukisan di atas kertas kepada Hajah Ngah Taib untuk terus diwarisi.

Penghasilan songket juga berkembang melalui perkahwinan Diraja sejak abad ke-15 Masihi dan golongan wanita istana telah membawa bersama-sama mereka alat-alat tenun serta penenun-penenun yang mahir untuk menghasilkan tenunan yang bermutu.

Manakala di Riau, Indonesia kegiatan bertenun dalam masyarakat Melayu Riau berterusan walaupun sesudah masa-masa kegemilangan kerajaan Melayu. Walau bagaimanapun, kegiatan tersebut mengalami penurunan apabila Riau berada di bawah penjajahan Belanda pada tahun 1913 sehinggalah Indonesia mencapai kemerdekaan. Jelasnya, di ibu kota Riau, iaitu Pekanbaru terdapat perkembangan tenunan songket Melayu yang dilihat semakin meningkat (Drs. Dr. H.O.k Nizami Jamil, temu bual peribadi, 17 Disember 2018).

Tengku Sayed Ali memerintah Siak dari tahun 1784-1810. Baginda juga dikenali dengan nama Sultan Assjaidis Syarif Ali Abdul Djalil Syaifuddin. Pada zaman pemerintahannya baginda telah memanggil seorang penenun dari Terengganu bernama Wan Siti Wan Karim untuk mengajar tenunan kepada anak-anak raja dan golongan bangsawan di Siak (Sasya Lestari \& Menul Teguh Riayanti, 2017). Wan Siti Wan Karim merupakan seorang penenun yang dibawa khas ke Siak pada masa pemerintahan Sultan Sayid Ali. Justeru wujud perhubungan yang baik antara Kerajaan Siak dengan Kerajaan Terengganu pada ketika itu. Sehingga kini, tenunan Melayu Riau yang masih bertahan ialah tenunan Siak. Sempena dengan namanya, tenunan songket Siak adalah berasal dari Siak Sri Indrapura. Jelasnya bagi kedua-dua negara, tenunan songket

\section{ii. Songket sebagai Sumber Sosioekonomi (Industri Desa)}

Perusahaan songket dan batik di negeri Terengganu ialah jenis perusahaan yang dikategorikan bawah kegiatan sosioekonomi orang Melayu (Wan Hashim Wan Teh, 1996). Perusahaan ini merupakan perusahaan warisan kerana ia memerlukan kemahiran dan ketekunan dalam penghasilannya (Wan Manang Wan Awang, temu bual peribadi, 18 Disember 2019).

Menurut Hill (1948), selepas Perang Dunia Kedua, perusahaan tenun telah dijalankan dalam lebih kurang seribu rumah kediaman di Terengganu dan lebih kurang tiga ribu rumah kediaman di Kelantan. Keistimewaan tekstil Melayu tradisional dikatakan mempunyai kaitan dengan budaya masyarakat dan setiap hasil yang dibuat adalah merupakan satu aktiviti berterusan yang berupa kemahiran yang diwarisi daripada generasi yang lalu (Yaacob Harun, 1989). Pembuatan tekstil, khususnya tenun dan songket lebih sinonim dengan kerja-kerja 
wanita dan gadis desa, disebabkan memerlukan tenaga fizikal, sebaliknya lebih memerlukan ketekunan, kesabaran dan kerajinan (Azah Aziz, 1990).

Pada peringkat awal pengeluaran tekstil di Terengganu dijalankan secara aktiviti keluarga. Namun, lama-kelamaan, kegiatan tersebut terus berkembang menjadi salah satu komoditi eksport terpenting. Ia berikutan kualiti tekstil yang dihasilkan adalah halus dan bermutu tinggi seperti yang terdapat pada kain sutera, kain songket dan kain batik (Arba'iyah Mohd Noor \& Norazilawati Abd Wahab, 2019).

Tenunan songket Siak pula diperkembangkan secara lebih meluas pada zaman pemerintahan Tengku Putera Sayed Kassim II. Baginda juga dikenali sebagai Sultan Assjaidis Sjarif Kasim II Abdul Djalil Sjaifuddin (1915-1946). Baginda mempunyai dua orang permaisuri iaitu permaisuri yang pertama dikenali Tengku Bih Sjarifah Lathifah Tengku Agung yang mangkat di Siak pada 1929. Baginda telah mengahwini dengan adinda Tengku Bih Sjarifah Lathifah Tengku Agung, iaitu Syarifah Fadlun Tengku Maharatu. Tengku Maharatu merupakan permaisuri yang begitu komited menekankan kemahiran bertenun dalam kalangan wanita Siak terutama untuk meningkatkan sumber ekonomi keluarga. Antara aspek tenunan yang popular ialah tenunan kain sutera, kain songket dengan hiasan benang emas, yang dikenali dengan kain sutera "Tenun Siak". Ia terdapat di Siak Sri Indrapura dan Bukit Batu tetapi yang masih bertahan sehingga sekarang ialah di Siak Sri Indrapura. Kebanyakan perusahaan songket adalah melibatkan penenun atau perajin yang terlatih dan ada yang melakukannya secara sambilan dan ada yang melakukan secara kecil sederhana sepenuh masa. Menurut Ros Diah Harlina Abdul Katar Ali (Temu bual peribadi, 18 Disember 2018) aktiviti penghasilan tenunan songket dilakukan di bengkel-bengkel khusus secara sepenuh masa dan ada pula yang melakukannya di rumah persendirian dengan sewaan peralatan tenunan secara sambilan. Namun, usaha tersebut sama ada di Terengganu mahupun di Riau bertujuan untuk menjana pendapatan keluarga di samping mengangkat martabat kesenian bangsa.

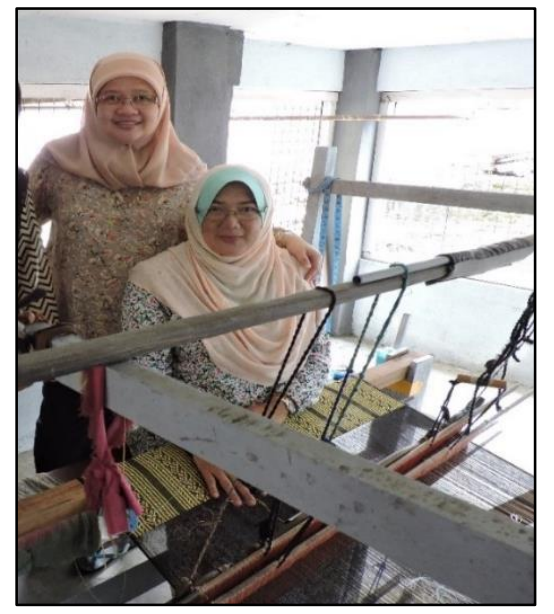

Gambar 1: Bersama Puan Siti Mariam Mamat, penenun di negeri Terengganu 


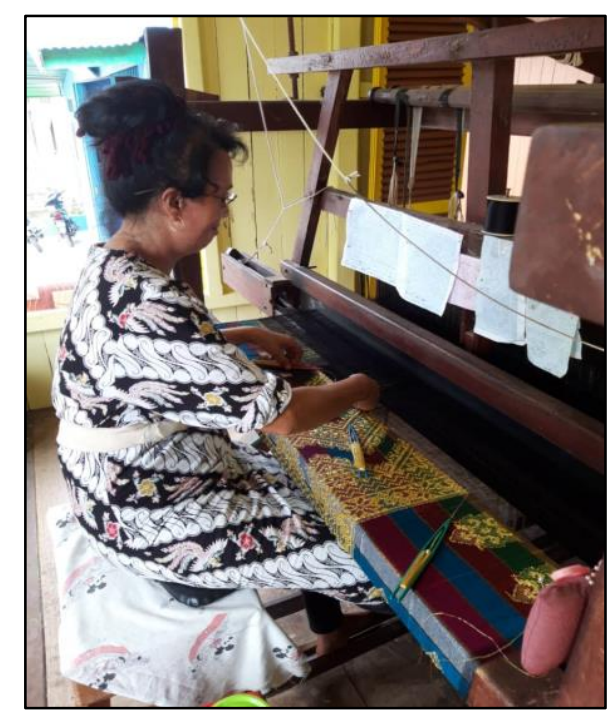

Gambar 2: Ibu Rohayah di Rumah Tenun Kampung Bandar, Riau, Indonesia

\section{iii. Songket sebagai Pakaian Adat}

Menyingkap dari segi sejarah, pada kurun yang ke-19 Masihi, persalinan orang Melayu secara tradisinya pernah memartabatkan seni tenunan songket sebagai busana kebesaran atau lambang pemakaian berprestij kerana hanya digayakan oleh golongan bangsawan berketurunan Diraja (Rahmah Bujang \& Nor Azlin Hamidon, 2002).

Walau bagaimanapun, perubahan masa telah melebarkan penggunaan songket dalam kalangan rakyat kecil dan sederhana dalam konteks apa yang dikenali sebagai 'Tradisi Rakyat' dan sering digunapakai dalam majlis-majlis keraian formal seperti perkahwinan, musim perayaan dan majlis Diraja (Siti Zainon Ismail, 1997).

Masyarakat Riau sering menggunakan tenunan songket ini sebagai bahan utama dalam pembuatan pakaian pengantin dan juga sebagai hadiah pernikahan kepada pasangan. Selain itu, ia dijadikan juga cenderahati berupa gantungan kunci berbentuk pakaian adat Riau dengan tempat perhiasan, tas dan lain-lain. Pemerintah daerah Riau menetapkan para pegawai Badan Usaha Milik Negara (BUMN), Pegawai Negeri Sipil (PNS), guru sekolah Taman Kanak-kanak (TK) hingga Sekolah Menengah Atas (SMA), serta lingkup pemerintahan kota mahupun pendesaan untuk memakai pakaian songket khususnya pada hari Jumaat (Sasya Lestari, Menul Teguh Riyanti, 2017). Meskipun ada usaha untuk merakyatkan pemakaian songket bagi kedua-dua negara namun, keistimewaan songket terus diabadikan sebagai pakaian tradisi yang kaya jati diri dan identiti tersendiri. Jelasnya, songket bukan sematamata busana biasa, tetapi dilestarikan sebagai alat yang menjunjung adat (Drs H. Abdul Malik, M.Pd, Haji Tenas Effendy, Haji Hasan Junus \& Drs. Auzar Thaher, M.S.2004). 


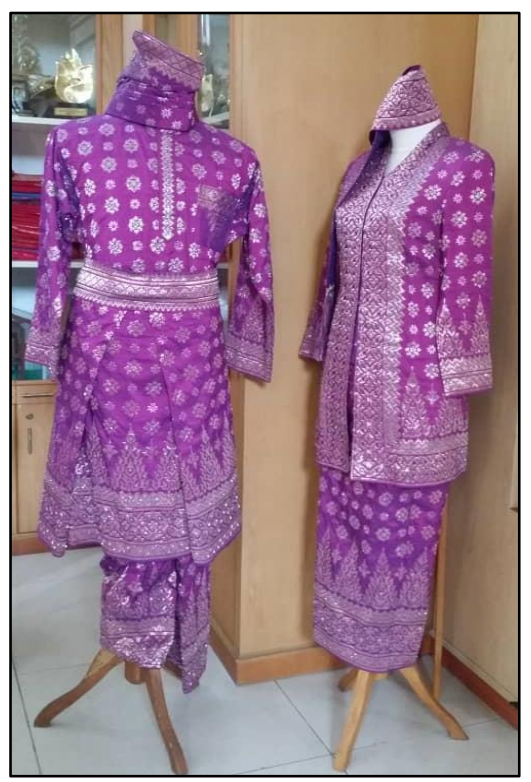

Gambar 3: Pakaian pengantin bagi masyarakat Riau

Sumber : Hajah Mursidah Osman

\section{iv. Motif-motif Songket}

Sehelai songket biasanya dihiasi motif atau ragam hiasnya. Songket perlu diperhalusi dengan pelbagai motif yang dapat memenuhi cita rasa si pemakai dari sudut artistik yang dilahirkan melalui pemikiran serta dizahirkan dengan penghayatan kalbu. Para penenun songket di Terengganu bijak mengolah bersumberkan alam untuk dijadikan motif dengan penuh makna dan simbolisme. Di sebalik gambaran alam yang diolah, tersimpul amalan bijak memberi makna yang indah sama ada dari segi falsafah, kias, petua, pedoman atau matlamat yang wujud secara tersurat dan tersirat.

Dalam hal ini orang Melayu mempergunakan segala kepandaian dan kebolehan daya fikir untuk membuat sesuatu penganalisisan dan perbandingan dalam konteks kehidupan mereka. Menariknya, akal dalam minda orang Melayu dilihat begitu bersebati dengan nilai budi dalam kehidupan mereka (Arba'iyah Aziz, 2018).

Begitu juga songket yang terdapat di Riau, tenunan songket juga adalah berdasarkan daripada sumber alam, iaitu flora, fauna dan kosmos. Motif yang sering digunakan adalah bersumberkan tumbuhan iaitu flora (Sasya Lestari \& Menul Teguh Riyanti, 2017). Motifmotif tersebut juga memiliki makna dan falsafah yang mencerminkan cara dan pandangan hidup manusia (Drs H. Abdul Malik, M.Pd, Haji Tenas Effendy, Haji Hasan Junus \& Drs.Auzar Thaher, M.S.2004).

Apa yang menarik, adunan motif-motif yang tercipta adalah hasil sandaran penenun kepada sumber inspirasi terhadap alam sekitar dalam lingkungan kehidupannya (Rujuk Gambar 4 - Gambar 7). 


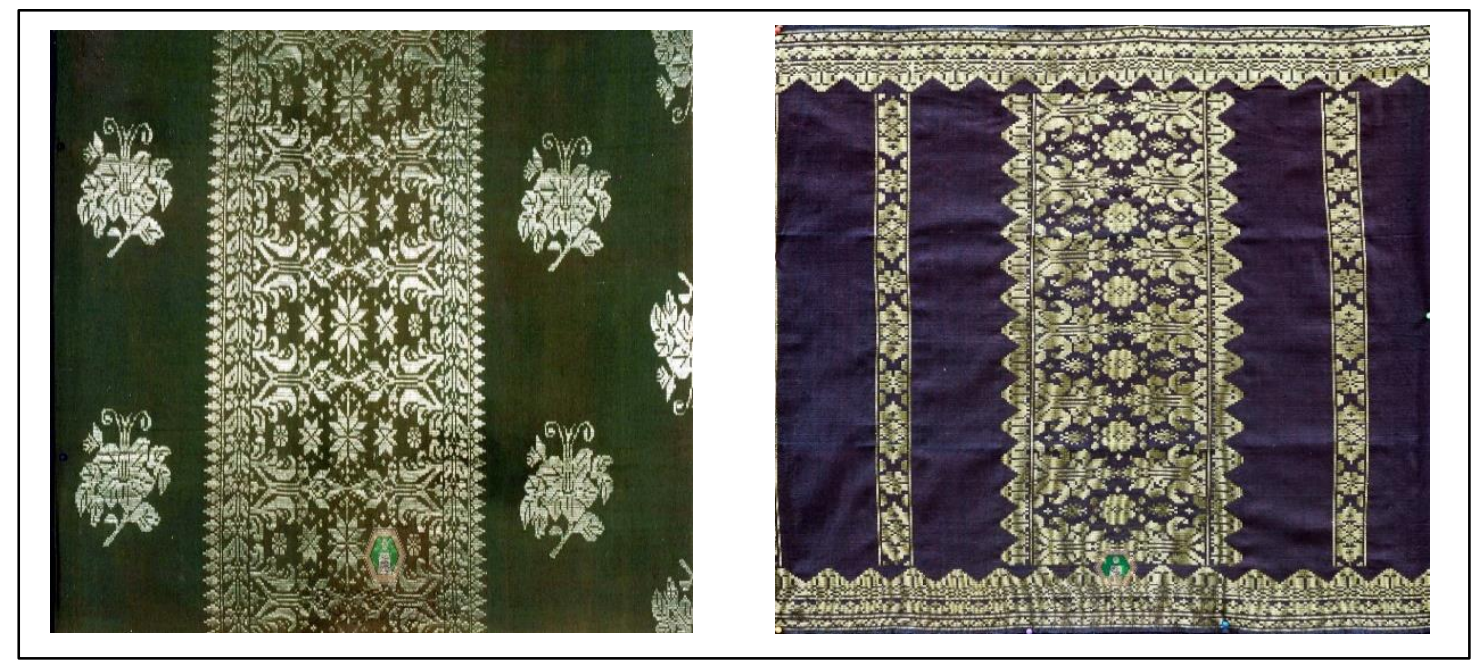

Gambar 4: Motif yang terdapat pada songket Terengganu Sumber: Muzium Negeri Terengganu

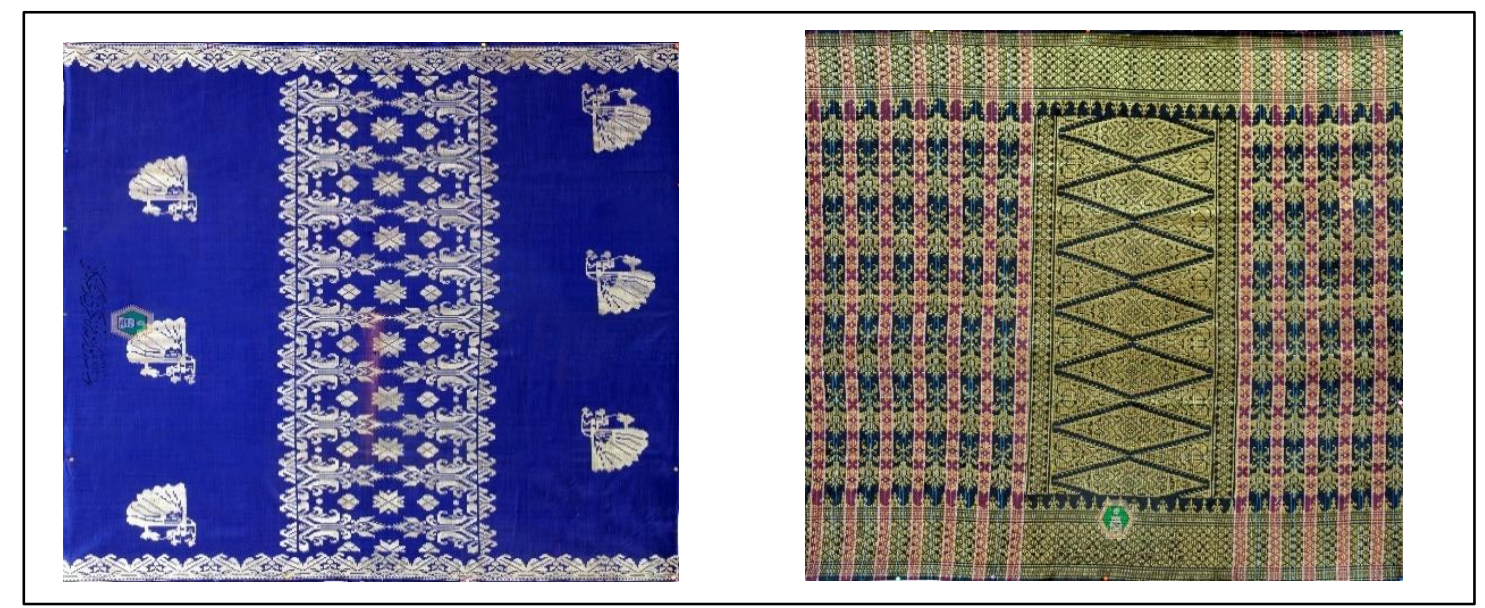

Gambar 5: Motif yang terdapat pada songket Terengganu Sumber: Muzium Negeri Terengganu

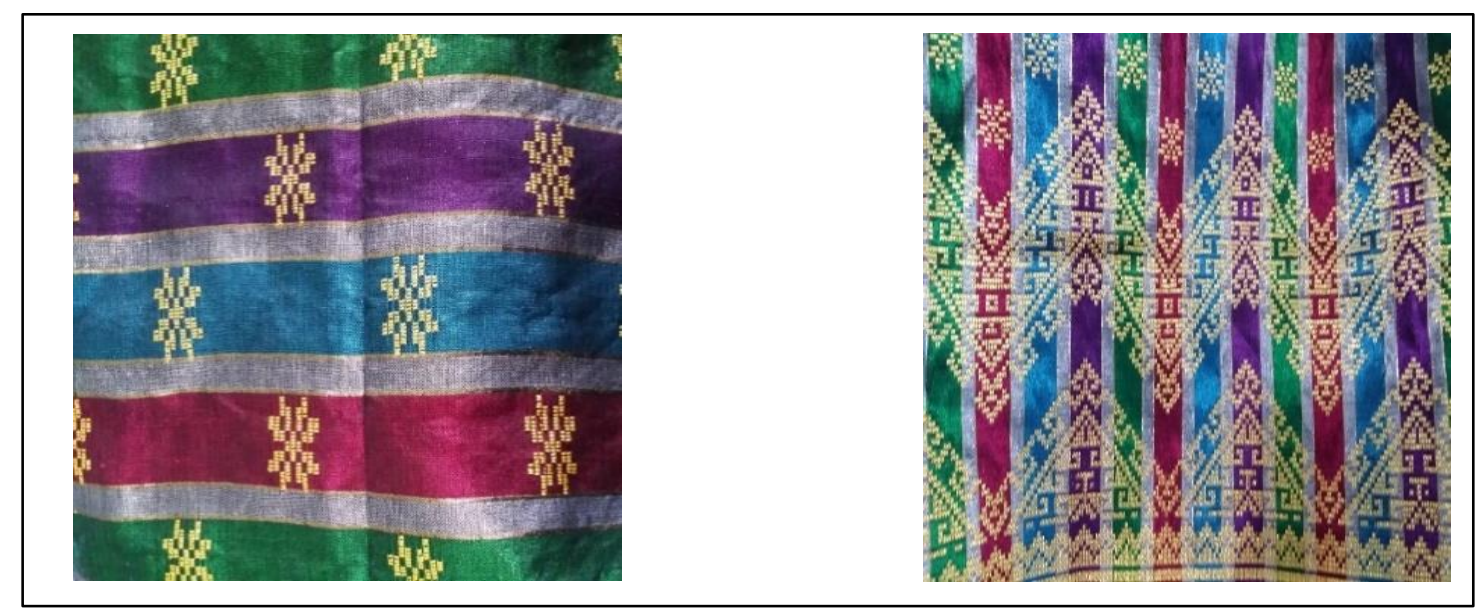

Gambar 6: Motif yang terdapat pada tenunan songket Riau Sumber: Hajah Mursidah Osman 


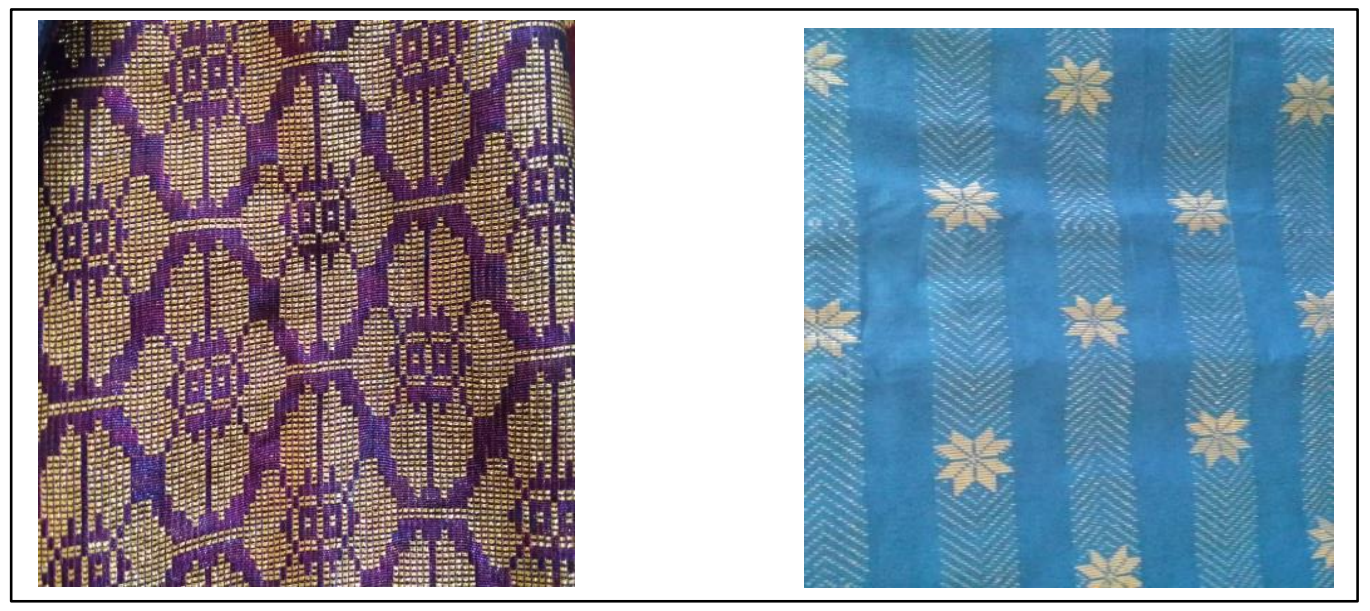

Gambar 7: Motif yang terdapat pada tenunan songket Riau

Sumber: Hajah Mursidah Osman

\section{Songket Sesantun Budaya}

Seni tenunan songket Terengganu mahupun songket Riau adalah tumpuan kepada kepentingannya dalam konteks norma dan adat tradisi masyarakat Melayu. Aspek kekukuhan dan keindahan songket bukan sahaja terletak pada tatacara pembikinan terhadap reka coraknya yang halus dan bermutu tinggi tetapi turut terarah pada motif-motifnya yang sarat dengan kepelbagaian makna dan falsafahnya. Di sebalik disiplin yang tinggi, ia memerlukan usaha dan kesabaran yang teguh seperti kata pepatah Melayu "sehari selembar benang lamalama menjadi kain". Songket yang dipakai pula adalah lambang gaya hidup berbudaya tinggi. Perlu dungkapkan, keagungan seni tenunan songket bukan hanya tergambar dari sudut luaran tetapi terangkum di dalamnya nilai falsafah yang sangat tinggi dari segi ukuran maknanya.

Songket adalah salah satu bahan tradisi yang menggambarkan jati diri dan keistimewaan bagi orang Melayu. Bahan tradisi ini merupakan suatu pendirian untuk melihat tradisi itu sebagai elemen asas yang mampu untuk membentuk dan mengukuhkan intipati budaya dan identitinya. Songket seharusnya menjadi satu entiti budaya yang hidup subur dan sesuai pada setiap masa. Berlandaskan prinsip tersebut, seni tenunan songket sememangnya wajar dinobatkan sebagai 'Seni Warisan Agung' yang perlu terus dipertahankan dan dipertingkatkan bagi tujuan penerusan dan kesinambungan seni warisan budaya Melayu serantau.

Sejajar dengan sejarahnya, songket masih tergolong sebagai busana yang berprestij meskipun ada usaha untuk merakyatkan pemakaiannya. Selain berupa pakaian yang boleh dipakai secara informal, penggunaan kain songket juga masih kukuh digunakan dalam upacara-upacara tradisi atau adat istiadat seperti majlis persandingan, perayaan, pertabalan, mengangkat sumpah jawatan tertinggi kerajaan, anugerah pingat kebesaran, pakaian (jubah) konvokesyen dan sebagainya. Ertinya, pemakaian tersebut banyak tersimpul pada makna dan pengertian budayanya iaitu satu cerminan susun atur dan sistem etika yang diwarisi masyarakat Melayu sejak dari dahulu lagi. Ketertiban ini juga menjelaskan bahawa ia bukan sekadar pakaian bagi memenuhi fungsi tertentu tetapi sebagai mewakili budaya bangsa yang kaya dan tinggi dengan nilai dan martabatnya.

Persepsi dan penerimaan orang Melayu terhadap institusi Diraja adalah begitu tinggi dan diberi penuh penghormatan dan kemuliaan. Oleh yang demikian, terdapat penenun- 
penenun yang mahir serta arif mengolah motif-motif songket yang bersesuaian dengan status golongan Diraja seperti motif pending, mahkota, keris, dan kota raja. Namun, dalam hal ini, pakaian bukan hanya semata-mata mempunyai fungsi sebagai penutup badan dan perhiasan tetapi juga boleh diterjemahkan sebagai lambang kuasa dan kewibawaan.

Kini, penggunaan kain tenunan songket dalam adat istiadat Diraja turut diperkembangkan. Para jemputan yang hadir ditentukan pula kod pakaian mereka agar sesuai dengan taraf dan darjatnya. Pakaian rasmi para pembesar dan pegawai kerajaan turut direka khas bagi mereka. Penetapan dan perbezaan warna dan reka bentuk pakaian rasmi para pembesar dan pegawai kerajaan tertentu telah digarispandukan oleh pihak yang diwakilkan raja yang berupa identifikasi simbolik tentang status seseorang dalam masyarakat atau sesuatu perlambangan keutamaan martabat atau prestij sosial kepada mereka. Kepatuhan untuk mematuhi kod pakaian yang telah ditetapkan adalah menunjukkan ketaatan dan pengabdian terhadap raja sebagai pemerintah dan kuasa yang tertinggi.

Pemegang-Pemegang Adat atau Ahli Lembaga Adat bagi kedua-dua negara akan sentiasa berperanan untuk terus melestarikan songket sebagai alat penyatuan rumpun bangsa Melayu yang unggul dari segi peradaban dan ketinggian keperibadiannya.

\section{Kesimpulan}

Perlu ditegaskan, keagungan seni tenunan songket ternyata bukan hanya tergambar dari sudut luaran tetapi terangkum di dalamnya nilai falsafah yang sangat tinggi ukuran maknanya. Dalam masyarakat Melayu serumpun terserlah budaya yang tinggi nilai kesantunannya. Justeru, hasil seni ini perlu terus dihayati sebagai seni Melayu yang mampu menterjemahkan keunikan dan keistimewaannya. Warisan ini adalah hasil daripada usaha murni dan sumbangan komuniti yang bukan semata-mata berteraskan kepada aspek ekonomi sematamata, tetapi kecenderungan yang merangkumi nilai sosial, budaya dan warisan. Sumbangan sebegini juga selaras dengan keperluan mewujudkan pembangunan modal insan khas untuk memperkembangkan seni warisan bangsa dan budaya serumpun di rantau ini. Bagaimanapun, kembalinya populariti songket tidak harus terhenti sebagai hasil seni tangan tempatan untuk pasaran dalam negara. Pernah digelar "Emporium of the East", songket semestinya diangkat ke martabat yang sewajarnya. Songket perlu terus berkembang dan diketengahkan ke persada global supaya aspek penghayatan ke atasnya akan terus gemilang dan terbilang.

Perlu dijelaskan, songket seni fabrik yang sangat halus dan tinggi mutu keasliannya, memperolehi tempat yang istimewa dalam sosio budaya masyarakat Melayu. Atas kapasiti kualiti dan keunikannya, maka sewajarnya songket diiktiraf dan diklasifikasikan sebagai ratu fabrik Melayu yang unggul. Kedudukan dan persepsi ini wajar dilestarikan meskipun rencah budaya itu sentiasa meniti arus kemajuan yang dinamik. Lazimnya, tradisi pemakaian songket adalah lengkap, sempurna dan tertib dengan perhiasan penuh, manakala pakaian Diraja pula begitu terserlah serinya dengan bertatah dan bersulam rapi penuh gemilang. Adalah lebih menarik apabila penampilan diserikan lagi dengan perhiasan cucuk sanggul, gelang tangan dan kaki, dokoh atau rantai panjang bertingkat serta tidak ketinggalan pending atau kepala tali pinggang bagi wanita, manakala sampin serta padanan tanjak di atas kepala bagi lelaki. Jelasnya, pemakaian busana Melayu ini adalah melambangkan tatasusila dan adat Melayu yang tinggi nilai peradaban dan kesopanannya. Meskipun usaha tersebut memperlihatkan nilai kemurniannya, namun haruslah tertegak sebagai pakaian yang sentiasa mampu menjunjung adat dan budayanya bersesuaian dengan sesuatu upacara, masa ataupun 
majlis kerana songket merupakan alat yang dapat menzahirkan serumpun bangsa dan sesantun budayanya.

\section{Rujukan}

Abdul Rahman Abdullah. (2000). Falsafah alam semesta di Nusantara. Kuala Lumpur: Utusan Publications \& Distributors Sdn. Bhd.

Abdul Rahman Embong. (2012). Terengganu merentasi tiga abad, Kesultanan, politik, ekonomi, agama dan budaya. Kuala Terengganu: Yayasan Diraja Sultan Mizan.

Arba'iyah Ab. Aziz. (2018). Simbolisme dalam motif songket Melayu Terengganu. Kuala Lumpur: Dewan Bahasa dan Pustaka.

Arba'iyah Mohd Noor \& Norazilawati Abd Wahab. (2019). "Pengaruh Indonesia Terhadap Tekstil di Terengganu pada Abad ke-19”. Jurnal Pengajian Melayu /Journal of Malay Studies (JOMAS), Jilid 30.

A.F.Yassin, Zam Ismail. (2002). Sejarah adat-istiadat Kesultanan Johor (1529-1855) Johor. Johor Bahru: Yayasan Warisan Johor.

Azah Aziz. (1990). Selayang kenangan. Kuala Lumpur: AMK Interaksi Sdn. Bhd.

Azah Aziz. (2006). Rupa dan gaya. Bangi: Penerbit Universiti Kebangsaan Malaysia.

Buhler, A. Eberhard, F. \& Marie- Louse, N. (1980). Indian Tie-dye Fabeics. Ahmedabad: Calio Museum.

Citra busana tradisional Malaysia, traditional costumes of Malaysia. Kementerian Kebudayaan, Kesenian dan Perlancongan Malaysia, Menara Dato' Onn, Pusat Dagangan Dunia Putra, Kuala Lumpur.

Drs H. Abdul Malik, M.Pd, Haji Tenas Effendy, Haji Hasan Junus \& Drs. Auzar Thaher, M.S.2004. Corak dan ragi tenun Melayu Riau. Yogyakarta: Balai Kajian dan Pengembangan Budaya Melayu bekerjasama dengan Penerbit AdiCita, Yogyakarta.

Fiona Kerlogue. (2004). The book of batik. London: Archipelago Press.

G.D G. Sieveking, "Recent archaeological discoveries in Malaya (1956)" Journal of Malayan Branch of the Royal Asiatic Society (JMBRAS). Vol. XVII Part I, Mac 1965, pp. 205206.

Habibah Abdul Jabbar, Nor Azlin Hamidon, Muhammad Ismail Ab Kadir \& Abdul Razak Abdul Jabbar. (2019). "Kain tenun Pahang dan kain tenun Sulawesi: Satu kajian perbandingan awal” . Jurnal Pengajian Melayu / Journal of Malay Literature (JOMAS), Jilid 30.

Haji Buyong Adil. (1974). Sejarah Terengganu. Kuala Lumpur: Dewan Bahasa dan Pustaka, Kementerian Pelajaran Malaysia. 
Haziah Hussin, Salmah Abu Mansor, Rahilah Omar, Hapsah Ismail \& Aminuddin Hassan. (2009). "Seni, Seni Hias, Seni Reka, Reka Bentuk dan Estetika daripada Persepsi Umum dan Orang Melayu". Jurnal Pengajian Melayu/ Journal of Malay Literature (JOMAS), Jilid 20.

Hill, A. H. May (1948). "The Weaving Industry in Terengganu”. Journal of Malayan Branch of the Royal Asiatic Society JMBRAS , 22 (3), pp. 75-84.

Jelani Harun. (2017). Zainal Abidin 111: Biografi Sultan yang adil dan alim. Kuala Lumpur: Dewan Bahasa dan Pustaka.

Koleksi busana anggun, kraftangan Malaysia. (2009). Kuala Lumpur: Perbadanan Kemajuan Kraftangan Malaysia.

Mohd Jamil Mukmin. (1994). Melaka pusat penyebaran Islam di Nusantara. Kuala Lumpur: Nurin Enterprise.

Muhamad Yusof Hashim. (1991). Terengganu Darul Iman, tradisi persejarahan Malaysia. Kuala Lumpur: Dewan Bahasa dan Pustaka.

Muhammad Isa Selamat. (2001). "Gagasan pembangunan \& kekuatan jati diri, Riau Menuju Jalan Puncak. Bengkalis ”. Warisan Riau, Pusat Kajian Warisan Melayu Riau.

Noor Azlina Yunus. (2008). Songket revolution. Bangsar, Kuala Lumpur: Yayasan Tunku Nur Zahirah.

Norazimah Zakaria. (2016). Kanon Melayu. Bangi: Penerbit Universiti Kebangsaan Malaysia.

Adat Istiadat Daerah Riau. (1977/1978). Riau: Proyek penelitian dan kebudayaan daerah Departemen Pendidikan dan Kebudayaan.

“Tradisi Johor-Riau”.(1987). Kertas kerja Hari Sastera 1983. Kuala Lumpur: Dewan Bahasa dan Pustaka.

Sulalatus Salatin. (2012). Sejarah Melayu Empayar Kesultanan Melayu Melaka. Kuala Lumpur: Balai Seni Visaual Negara.

U.U. Hamidy. (1988). Riau sebagai pusat bahasa dan kebudayaan Melayu. Riau: Bumiputra.

Rahmah Bujang \& Nor Azlin Hamidon. (2002). Kesenian Melayu. Kuala Lumpur: Akademi Pengajian Melayu, Universiti Malaya

Rogayah A. Hamid, Mariam Salim. (2006). Siri kajian Kesultanan Melayu Terengganu. Kuala Lumpur: Dewan Bahasa dan Pustaka.

Sasya Lestari, Menul Teguh Riyanti, Program studi design komunikasi visual. FSRD Universiti Trisaksi Dimensi DKV, Vol.2, No.1 April 2017. 
Selvanayagam, Grace Impan (1991). Songket: Malaysia's Woven Treasure. Singapore: Oxford University Press Pte. Ltd.

Tradition \& continuity: Woven and decorated textiles of the Malay Peninsular. (2013). Kuala Lumpur: Islamic Arts Museum Malaysia.

Profil Propinsi Republik Indonesia, Riau. Riau: Pemrakarsa.

Arsitektur Traditional Daerah Riau. (1986/1987). Riau: Departmen Pendidikan dan Kebudayaan, Proyek Iventarisasi dan Dokumentasi Kebudayaan Daerah.

Sejarah Daerah Riau. Cetakan ke-2 (1986/1987). Riau: Departmen Pendidikan dan Kebudayaan, Proyek Iventarisasi dan Dokumentasi Kebudayaan Daerah. 